\title{
Imaginary Friends
}

\author{
Jairo Zaldua \\ Collaborative Artist \\ Flat 11, Longley House \\ 244 Tufnell Park Road \\ London N19 5HB, UK \\ nicoelajairo@hotmail.com
}

\author{
Nicola Green \\ Collaborative Artist \\ Flat 11, Longley House \\ 244 Tufnell Park Road \\ London N19 5HB, UK \\ nicoelajairo@hotmail.com
}

\section{INTRODUCTION}

Where do the imaginary friends go when their human creators grow up? Imaginary friends are often associated with children, but what about adults?

The role of the imagination is often discouraged from childhood - the wish to play and explore. Why have an imaginary friend? What purpose do they still serve? Where has the imaginary been in the story of your life? Can it be an antidote to loneliness, or is it the need for something other? Are you still intrigued?

The aim of this on-going project is to create an interaction and dialogue with the public both online and also as a physical activity.

\section{ORIGINS OF THE PROJECT}

Imaginary Friends originally began as part of a conceptual project at the CMR gallery in Redruth in 2013. With the combination of a basic portable screen-printing workshop and an installation, we invited the public to create a print from a range of silk-screens provided based on their idealised 'imaginary friend' and we encouraged them to write a brief description to accompany the imagery displayed on the walls.

The response encouraged us to explore this further at Hale End Library in Walthamstow, with more of an emphasis on children. Further success led us to a series of offsite workshops, which included Sadler's Wells Theatre, Hackney Wicked Festival and Half Baked nightclub.

This culminated in a prototype exhibition at the Kentish Town Health Centre in 2014 over three consecutive days. We extended the theme to include an installation, interactive workshops and a dance performance. The public experienced a visual journey of many dimensions, where they were also given set tasks and moments of contemplation. When the event was completed, we requested feedback from the attendees, although the comments were positive overall, we did receive some critical but constructive opinions that were both applicable and significant to the future of the project.

\section{WHAT DID WE LEARN FROM THE EXPERIENCE AND WHAT IS REQUIRED?}

Our original research made it apparent that although we had the foundations of an interesting concept, limited resources and lack of funding (the project was self-funded) were clearly an impediment to the potential and delivery of Imaginary Friends. Of particular note, some attendees said:

- Guidance and more clarity was needed for the journey.

- A decent meeting point and a final convergence with hospitality extended, in order to encourage conversation and reflection.

- More props and interaction as well as elements of surprise on the journey, as it was probably too short and slightly unfinished.

- Some of the ideas could have been taken further and may have made for a more evocative and personal experience.

- Extra staff to enable the event to run successfully.

To overcome these obstacles, we stepped back and concentrated on what was required to enhance our reputation, increase our visibility and fine-tune every aspect of the project. Further research on the subject matter and speculation on what we could realistically achieve with regard to budget and application for funding. This required interviewing and networking with various individuals and practitioners and also seeking advice. 


\section{HOW DO WE AIM TO ACHIEVE THIS?}

In 2014 we set up an online Facebook profile titled 'Imaginary Friend Arts, which features a selection of our imagery and various quotes linked to the subject matter. We have managed to generate 3,360 followers at present and the site is on-going.

The objective is to create a stronger interactive element to the page and invite the public to follow the steps below:

(a) Write a brief description (no more than a few sentences) of your idealised imaginary friend.

(b) Name your character.

(c) Email Jairo and Nicola with the heading 'IMAGINARY FRIEND' to our email address.

Next, we will create an image based on or as a response to your description and post the results online, when completed. This could take the form of a screen print, collage, c-print or something other. Examples can be viewed online on Facebook (https://www.facebook.com/imaginaryfriendarts).

This idea has been promoted online and through selected friends, but we would like to utilise other more tangible means of advertising, i.e. postcards, leaflets, adverts or articles in local press and word of mouth. This could be distributed at colleges, bars and art centres.

The aim is to create an online event/community that will eventually materialise into a physical event/exhibition in London, which might incorporate installation, video, slides, performance and sound.

\section{HOW WILL THE PUBLIC BENEFIT FROM IMAGINARY FRIENDS?}

This could be an outlet for creativity and selfexpression through means of role playing, acting out ideas and imaginary scenarios, resolving problems and an antidote to loneliness. An overall therapeutic experience that could be both external and internal - the chance to share a story or keep a secret. Either way, a meeting place for Imaginary friends.

\section{IDEAS AND INFLUENCES}

Possible ideas that would require further thought and collaboration could include an APP or a game, an online story, which includes some of the characters from the Facebook page and a booklet of the images created with the quotes enclosed.

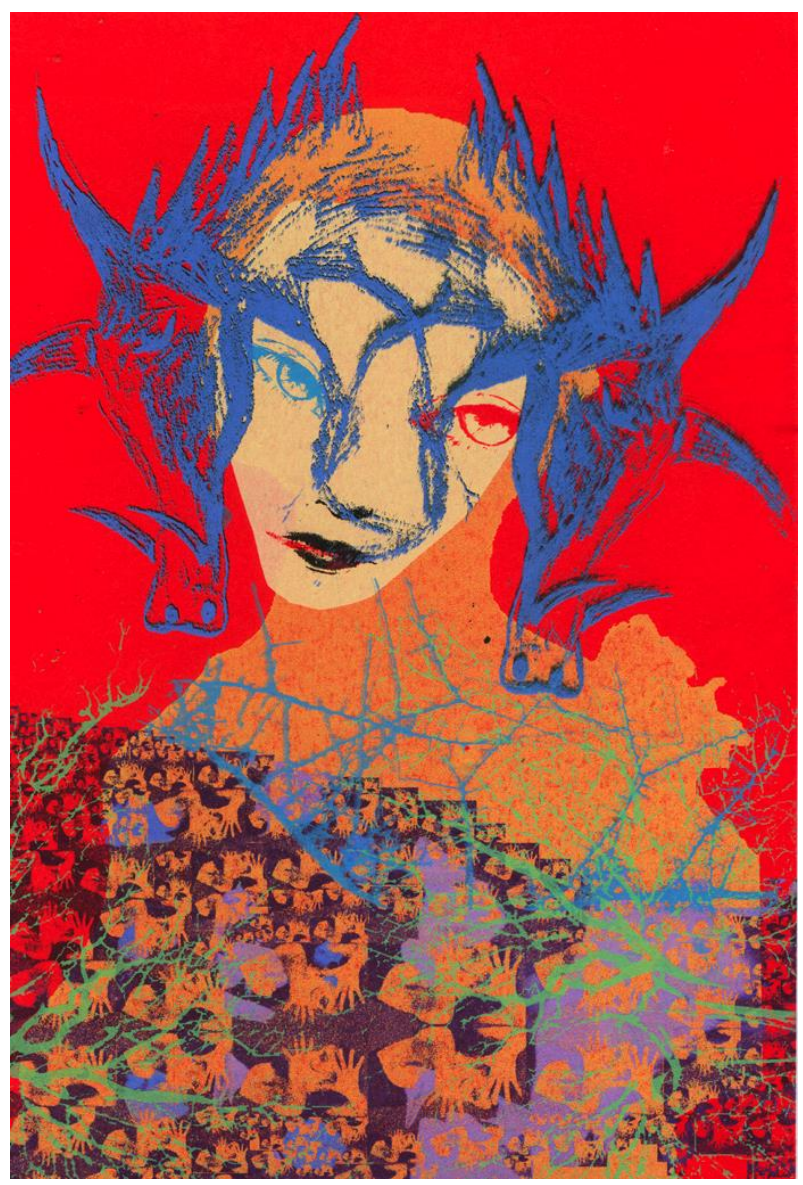

Figure 1: Where do they go when their human creators grow up? Screen-print by Jairo Zaldua and Nicola Green

Taken from their Imaginary Friends series (c.2014).

Notable influences from films, literature and the arts include: Donnie Darko, Uncle Boomnee Who Can Recall His Past Lives, Into the Realms of the Unreal, Harvey, Foster's Home for Imaginary Friends, Twin Peaks; Memoirs of an Imaginary Friend, the short stories of Yoko Agawa and the fiction of Haruki Murakami; the art installations of Tino Segall and Georgina Starr.

Our online page was influenced by the photo-blog Humans of New York, created by photographer Brandon Stanton in 2010. This is s a blog and a book of street interviews and portraits collected on the streets of New York City.

\section{REFERENCES}

Gleason, T., Sebanc, T. R., Hartup, A. M., and Willard, W. (2000) Imaginary Companions of pre School Children, Developmental Psychology, 36(4), July 2000.

Hoff, E. V. (2004-2005) A Friend Living Inside Me - The Forms and Functions of Imaginary Companions. Lund University, Sweden.

Hurlock, E. and Burstein, M. (1932) The Imaginary Playmate: A questionnaire study. 